\title{
An extension of asymptotically lacunary statistical equivalence set sequences
}

\author{
Uğur Ulusu ${ }^{1 *}$ and Ekrem Savaş²
}

\footnotetext{
Correspondence: ulusu@aku.edu.tr ${ }^{1}$ Department of Mathematics, Faculty of Science and Literature, Afyon Kocatepe University, Afyonkarahisar, 03200, Turkey Full list of author information is available at the end of the article
}

\begin{abstract}
This paper presents, for sequences of sets, the notions of asymptotically lacunary statistical equivalence (in the sense of Wijsman) of multiplicity L, strongly asymptotically lacunary $p$-equivalence (in the sense of Wijsman) of multiplicity $L$ and strongly Cesàro asymptotically $p$-equivalence (in the sense of Wijsman) of multiplicity L. In addition to these definitions, inclusion theorems are also presented.
\end{abstract}

Keywords: asymptotically equivalence; statistical convergence; lacunary sequence; Cesàro summability; sequences of sets; Wijsman convergence

\section{Introduction and background}

The concept of convergence of sequences of numbers has been extended by several authors to convergence of sequences of sets. The one of these such extensions considered in this paper is the concept of Wijsman convergence (see [1-8]). Nuray and Rhoades [4] extended the notion of convergence of set sequences to statistical convergence, and gave some basic theorems. It should be noted that lacunary statistical convergence was studied by Fridy and Orhan (see [9]). Ulusu and Nuray [5] defined the Wijsman lacunary statistical convergence of sequence of sets, and considered its relation with Wiijsman statistical convergence.

Marouf [10] presented definitions for asymptotically equivalent sequences and asymptotic regular matrices. Patterson [11] extended these concepts by presenting an asymptotically statistical equivalent analog of these definitions and natural regularity conditions for nonnegative summability matrices. Patterson and Savaş [12] extended the definitions which were presented in [11] to lacunary sequences and also, in [13], they studied an extension asymptotically lacunary statistically equivalent sequences. In addition to these definitions, natural inclusion theorems were presented. Savaş [14] presented $\mathcal{I}$-asymptotically lacunary statistical equivalent sequences. Furthermore, Ulusu and Nuray [5] extended the definitions presented in [12] to sequences of sets which is Wijsman sense. Also natural inclusion theorems were presented.

In this paper we introduce the concept of strongly asymptotically lacunary $p$-equivalence (in the sense of Wijsman) of multiplicity $L$ and strongly Cesàro asymptotically $p$ equivalence (in the sense of Wijsman) of multiplicity $L$ by using the sequence $p=\left(p_{k}\right)$ which is the sequence of positive real numbers. In addition to these definitions, natural inclusion theorems are presented.

Before continuing with this paper we present some definitions and preliminaries. 
Definition 1.1 [10] Two nonnegative sequences $x=\left(x_{k}\right)$ and $y=\left(y_{k}\right)$ are said to be asymptotically equivalent if

$$
\lim _{k} \frac{x_{k}}{y_{k}}=1
$$

(denoted by $x \sim y$ ).

Let $(X, \rho)$ be a metric space. For any point $x \in X$ and any non-empty subset $A$ of $X$, we define the distance from $x$ to $A$ by

$$
d(x, A)=\inf _{a \in A} \rho(x, A) .
$$

Definition 1.2 [1] Let $(X, \rho)$ be a metric space. For any non-empty closed subsets $A, A_{k} \subseteq X$, we say that the sequence $\left\{A_{k}\right\}$ is Wijsman convergent to $A$ if

$$
\lim _{k \rightarrow \infty} d\left(x, A_{k}\right)=d(x, A)
$$

for each $x \in X$. In this case we write $W-\lim A_{k}=A$.

Definition 1.3 [15] The sequence $x=\left(x_{k}\right)$ is said to be statistically convergent to the number $L$ if for every $\varepsilon>0$,

$$
\lim _{n} \frac{1}{n}\left|\left\{k \leq n:\left|x_{k}-L\right| \geq \varepsilon\right\}\right|=0
$$

(denoted by $s t$ - $\left.\lim x_{k}=L\right)$.

Definition 1.4 [16] The sequence $x=\left(x_{k}\right)$ is said to be strongly Cesàro summable to the number $L$ if

$$
\lim _{n \rightarrow \infty} \frac{1}{n} \sum_{k=1}^{n}\left|x_{k}-L\right|=0
$$

(denoted by $\left.x_{k} \stackrel{\left|\sigma_{1}\right|}{\rightarrow} L\right)$.

Definition 1.5 [4] Let $(X, \rho)$ be a metric space. For any non-empty closed subsets $A, A_{k} \subseteq X$, we say that the sequence $\left\{A_{k}\right\}$ is Wijsman statistical convergent to $A$ if $\left\{d\left(x, A_{k}\right)\right\}$ is statistically convergent to $d(x, A)$; i.e., for $\varepsilon>0$ and for each $x \in X$,

$$
\lim _{n \rightarrow \infty} \frac{1}{n}\left|\left\{k \leq n:\left|d\left(x, A_{k}\right)-d(x, A)\right| \geq \varepsilon\right\}\right|=0 .
$$

In this case we write $s t-\lim _{W} A_{k}=A$ or $A_{k} \rightarrow A(W S)$.

Definition 1.6 [4] Let $(X, \rho)$ be a metric space. For any non-empty closed subsets $A, A_{k} \subseteq X$, we say that $\left\{A_{k}\right\}$ is Wijsman strongly Cesàro summable to $A$ if for each $x \in X$,

$$
\lim _{n \rightarrow \infty} \frac{1}{n} \sum_{k=1}^{n}\left|d\left(x, A_{k}\right)-d(x, A)\right|=0
$$

In this case we write $A_{k} \rightarrow A\left(\left[W \sigma_{1}\right]\right)$ or $A_{k} \stackrel{\left[W \sigma_{1}\right]}{\rightarrow} A$. 
By a lacunary sequence we mean an increasing integer sequence $\theta=\left\{k_{r}\right\}$ such that $k_{0}=0$ and $h_{r}=k_{r}-k_{r-1} \rightarrow \infty$ as $r \rightarrow \infty$. Throughout this paper the intervals determined by $\theta$ will be denoted by $I_{r}=\left(k_{r-1}, k_{r}\right]$, and the ratio $\frac{k_{r}}{k_{r-1}}$ will be abbreviated by $q_{r}$.

Definition 1.7 [5] Let $(X, \rho)$ a metric space and $\theta=\left\{k_{r}\right\}$ be a lacunary sequence. For any non-empty closed subsets $A, A_{k} \subseteq X$, we say that the sequence $\left\{A_{k}\right\}$ is Wijsman lacunary statistical convergent to $A$ if $\left\{d\left(x, A_{k}\right)\right\}$ is lacunary statistically convergent to $d(x, A)$; i.e., for $\varepsilon>0$ and for each $x \in X$,

$$
\lim _{r} \frac{1}{h_{r}}\left|\left\{k \in I_{r}:\left|d\left(x, A_{k}\right)-d(x, A)\right| \geq \varepsilon\right\}\right|=0 .
$$

In this case we write $S_{\theta}-\lim _{W}=A$ or $A_{k} \rightarrow A\left(W S_{\theta}\right)$.

The next definition is natural combination of Definition 1.1 and Definition 1.7.

Definition 1.8 [6] Let $(X, \rho)$ be a metric space and $\theta$ be a lacunary sequence. For any nonempty closed subsets $A_{k}, B_{k} \subseteq X$ such that $d\left(x, A_{k}\right)>0$ and $d\left(x, B_{k}\right)>0$ for each $x \in X$. We say that the sequences $\left\{A_{k}\right\}$ and $\left\{B_{k}\right\}$ are asymptotically lacunary statistical equivalent (in the sense of Wijsman) of multiplicity $L$ if for every $\varepsilon>0$ and each $x \in X$,

$$
\lim _{r} \frac{1}{h_{r}}\left|\left\{k \in I_{r}:\left|\frac{d\left(x, A_{k}\right)}{d\left(x, B_{k}\right)}-L\right| \geq \varepsilon\right\}\right|=0
$$

(denoted by $\left\{A_{k}\right\} \stackrel{W S_{\theta}^{L}}{\sim}\left\{B_{k}\right\}$ ) and simply asymptotically lacunary statistical equivalent (in the sense of Wijsman) if $L=1$.

As an example, consider the following sequences:

$$
A_{k}:= \begin{cases}\left\{(x, y) \in \mathbb{R}^{2}: x^{2}+(y-1)^{2}=\frac{1}{k}\right\}, & \text { if } k_{r-1}<k<k_{r-1}+\left[\sqrt{h_{r}}\right] \text { and } \\ & k \text { is a square integer, } \\ \{(0,0)\}, & \text { otherwise, }\end{cases}
$$

and

$$
B_{k}:= \begin{cases}\left\{(x, y) \in \mathbb{R}^{2}: x^{2}+(y+1)^{2}=\frac{1}{k}\right\}, & \text { if } k_{r-1}<k<k_{r-1}+\left[\sqrt{h_{r}}\right] \text { and } \\ & k \text { is a square integer, } \\ \{(0,0)\}, & \text { otherwise. }\end{cases}
$$

Definition 1.9 [6] Let $(X, \rho)$ be a metric space and $\theta$ be a lacunary sequence. For any nonempty closed subsets $A_{k}, B_{k} \subseteq X$ such that $d\left(x, A_{k}\right)>0$ and $d\left(x, B_{k}\right)>0$ for each $x \in X$. We say that the sequences $\left\{A_{k}\right\}$ and $\left\{B_{k}\right\}$ are strongly asymptotically lacunary equivalent (in the sense of Wijsman) of multiplicity $L$ if for each $x \in X$,

$$
\lim _{r} \frac{1}{h_{r}} \sum_{k \in I_{r}}\left|\frac{d\left(x, A_{k}\right)}{d\left(x, B_{k}\right)}-L\right|=0
$$

(denoted by $\left\{A_{k}\right\} \stackrel{\left[W_{N}\right]_{\theta}^{L}}{\sim}\left\{B_{k}\right\}$ ) and simply strongly asymptotically lacunary equivalent (in the sense of Wijsman) if $L=1$. 


\section{Main results}

Let $(X, \rho)$ be a metric space. For any non-empty closed subsets $A_{k}, B_{k} \subseteq X$, we define $d\left(x ; A_{k}, B_{k}\right)$ as follows:

$$
d\left(x ; A_{k}, B_{k}\right)= \begin{cases}\frac{d\left(x, A_{k}\right)}{d\left(x, B_{k}\right)}, & x \notin A_{k} \cup B_{k}, \\ L, & x \in A_{k} \cup B_{k} .\end{cases}
$$

Definition 2.1 Let $(X, \rho)$ be a metric space, $\theta$ be a lacunary sequence and $p=\left(p_{k}\right)$ be a sequence of positive real numbers. For any non-empty closed subsets $A_{k}, B_{k} \subseteq X$, we say that the sequences $\left\{A_{k}\right\}$ and $\left\{B_{k}\right\}$ are strongly asymptotically lacunary $p$-equivalent (in the sense of Wijsman) of multiplicity $L$ if for each $x \in X$,

$$
\lim _{r} \frac{1}{h_{r}} \sum_{k \in I_{r}}\left|d\left(x ; A_{k}, B_{k}\right)-L\right|^{p_{k}}=0
$$

(denoted by $\left\{A_{k}\right\} \stackrel{[W N]_{\theta}^{L_{(p)}}}{\sim}\left\{B_{k}\right\}$ ) and simply strongly asymptotically lacunary $p$-equivalent (in the sense of Wijsman) if $L=1$.

If we take $p=p_{k}$ for all $k \in \mathbb{N}$ we write $\left\{A_{k}\right\} \stackrel{[W N]_{\theta}^{L_{p}}}{\sim}\left\{B_{k}\right\}$ instead of $\left\{A_{k}\right\} \stackrel{[W N]_{\theta}^{L_{(p)}} \sim}{\sim}\left\{B_{k}\right\}$.

Theorem 2.1 Let $(X, \rho)$ be a metric space, $\theta=\left\{k_{r}\right\}$ be a lacunary sequence and $A_{k}, B_{k}$ be non-empty closed subsets of $X$; then

(i) $\left\{A_{k}\right\} \stackrel{[W N]_{\theta}^{L_{p}}}{\sim}\left\{B_{k}\right\} \Rightarrow\left\{A_{k}\right\} \stackrel{W S_{\theta}^{L}}{\sim}\left\{B_{k}\right\}$,

(ii) $d\left(x, A_{k}\right)=O\left(d\left(x, B_{k}\right)\right)$ and $\left\{A_{k}\right\} \stackrel{W S_{\theta}^{L}}{\sim}\left\{B_{k}\right\} \Rightarrow\left\{A_{k}\right\} \stackrel{[W N]_{\theta}^{L_{p}}}{\sim}\left\{B_{k}\right\}$.

Proof (i) Let $\varepsilon>0$ and $\left\{A_{k}\right\} \stackrel{[W N]_{\theta}^{L_{p}}}{\sim}\left\{B_{k}\right\}$. Then we can write

$$
\begin{aligned}
\sum_{k \in I_{r}}\left|d\left(x ; A_{k}, B_{k}\right)-L\right|^{p} & \geq \sum_{\substack{k \in I_{r} \\
\left|d\left(x ; A_{k}, B_{k}\right)-L\right| \geq \varepsilon}}\left|d\left(x ; A_{k}, B_{k}\right)-L\right|^{p} \\
& \geq \varepsilon^{p} \cdot\left|\left\{k \in I_{r}:\left|d\left(x ; A_{k}, B_{k}\right)-L\right| \geq \varepsilon\right\}\right| .
\end{aligned}
$$

Therefore, $\left\{A_{k}\right\} \stackrel{W S_{\theta}^{L}}{\sim}\left\{B_{k}\right\}$.

(ii) Suppose that $d\left(x, A_{k}\right)=O\left(d\left(x, B_{k}\right)\right)$ and $\left\{A_{k}\right\} \stackrel{W S_{\theta}^{L}}{\sim}\left\{B_{k}\right\}$. Then we can assume that

$$
\left|d\left(x ; A_{k}, B_{k}\right)-L\right| \leq M
$$

for all $k$ and for each $x \in X$. Let $\varepsilon>0$ be given and $N_{\varepsilon}$ be such that

$$
\frac{1}{h_{r}}\left|\left\{k \in I_{r}:\left|d\left(x ; A_{k}, B_{k}\right)-L\right| \geq\left(\frac{\varepsilon}{2}\right)^{\frac{1}{p}}\right\}\right| \leq \frac{\varepsilon}{2 K^{p}}
$$

for all $r>N_{\varepsilon}$ for each $x \in X$. Let

$$
L_{k}=\left\{k \in I_{r}:\left|d\left(x ; A_{k}, B_{k}\right)-L\right| \geq\left(\frac{\varepsilon}{2}\right)^{\frac{1}{p}}\right\} .
$$


Now, for all $r>N_{\varepsilon}$ we have

$$
\begin{aligned}
\frac{1}{h_{r}} \sum_{k \in I_{r}}\left|d\left(x ; A_{k}, B_{k}\right)-L\right|^{p} & =\frac{1}{h_{r}} \sum_{k \in L_{k}}\left|d\left(x ; A_{k}, B_{k}\right)-L\right|^{p}+\frac{1}{h_{r}} \sum_{k \notin L_{k}}\left|d\left(x ; A_{k}, B_{k}\right)-L\right|^{p} \\
& \geq \frac{1}{h_{r}} \frac{h_{r} \varepsilon}{2 K^{p}} K^{p}+\frac{1}{h_{r}} h_{r} \frac{\varepsilon}{2} .
\end{aligned}
$$

Therefore, $\left\{A_{k}\right\} \stackrel{[W N]_{\theta}^{L_{p}}}{\sim}\left\{B_{k}\right\}$.

Theorem 2.2 Let $(X, \rho)$ be a metric space and $A_{k}, B_{k}$ be non-empty closed subsets of $X$. If $\theta=\left\{k_{r}\right\}$ is a lacunary sequence and $\sup _{k} p_{k}=H$, then

$$
\left\{A_{k}\right\} \stackrel{[W N]_{\theta}^{L_{(p)}}}{\sim}\left\{B_{k}\right\} \quad \Rightarrow \quad\left\{A_{k}\right\} \stackrel{W S_{\theta}^{L}}{\sim}\left\{B_{k}\right\}
$$

Proof Suppose that $\sup _{k} p_{k}=H$ and $\left\{A_{k}\right\} \stackrel{[W N]_{\theta}^{L(p)}}{\sim}\left\{B_{k}\right\}$. Let $\varepsilon>0$ be given. Then

$$
\begin{aligned}
& \frac{1}{h_{r}} \sum_{k \in I_{r}}\left|d\left(x ; A_{k}, B_{k}\right)-L\right|^{p_{k}}=\frac{1}{h_{r}} \sum_{\substack{k \in I_{r} \\
\left|d\left(x ; A_{k}, B_{k}\right)-L\right| \geq \varepsilon}}\left|d\left(x ; A_{k}, B_{k}\right)-L\right|^{p_{k}} \\
& +\frac{1}{h_{r}} \sum_{\substack{k \in I_{r} \\
\left|d\left(x ; A_{k}, B_{k}\right)-L\right|<\varepsilon}}\left|d\left(x ; A_{k}, B_{k}\right)-L\right|^{p_{k}} \\
& \geq \frac{1}{h_{r}} \sum_{\substack{k \in I_{r} \\
\left|d\left(x ; A_{k}, B_{k}\right)-L\right| \geq \varepsilon}}\left|d\left(x ; A_{k}, B_{k}\right)-L\right|^{p_{k}} \\
& \geq \frac{1}{h_{r}} \sum_{\substack{k \in I_{r} \\
\left|d\left(x ; A_{k}, B_{k}\right)-L\right| \geq \varepsilon}}(\varepsilon)^{p_{k}}
\end{aligned}
$$

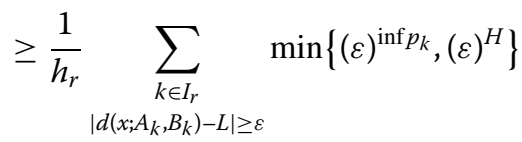

$$
\begin{aligned}
& \geq \frac{1}{h_{r}}\left|\left\{k \in I_{r}:\left|d\left(x ; A_{k}, B_{k}\right)-L\right| \geq \varepsilon\right\}\right| \cdot \min \left\{(\varepsilon)^{\inf p_{k}},(\varepsilon)^{H}\right\} .
\end{aligned}
$$

Hence, $\left\{A_{k}\right\} \stackrel{W S_{\theta}^{L}}{\sim}\left\{B_{k}\right\}$.

Theorem 2.3 Let $(X, \rho)$ be a metric space and $A_{k}, B_{k}$ be non-empty closed subsets of $X$. If $d\left(x, A_{k}\right)=O\left(d\left(x, B_{k}\right)\right)$ and $0<h=\inf _{k} p_{k} \leq \sup _{k} p_{k}=H<\infty$, then

$$
\left\{A_{k}\right\} \stackrel{W S_{\theta}^{L}}{\sim}\left\{B_{k}\right\} \Rightarrow\left\{A_{k}\right\} \stackrel{[W N]_{\theta}^{L}(p)}{\sim}\left\{B_{k}\right\}
$$

Proof Suppose that $d\left(x, A_{k}\right)=O\left(d\left(x, B_{k}\right)\right)$ and $\varepsilon>0$ is given. Since $d\left(x, A_{k}\right)=O\left(d\left(x, B_{k}\right)\right)$ there exists an integer $M$ such that

$$
\left|d\left(x ; A_{k}, B_{k}\right)-L\right| \leq M
$$


for all $k$ and for each $x \in X$. Then

$$
\begin{aligned}
\frac{1}{h_{r}} \sum_{k \in I_{r}}\left|d\left(x ; A_{k}, B_{k}\right)-L\right|^{p_{k}=} & \frac{1}{h_{r}} \sum_{\substack{k \in I_{r} \\
\left|d\left(x ; A_{k}, B_{k}\right)-L\right| \geq \varepsilon}}\left|d\left(x ; A_{k}, B_{k}\right)-L\right|^{p_{k}} \\
& +\frac{1}{h_{r}} \sum_{\substack{k \in I_{r} \\
\left|d\left(x ; A_{k}, B_{k}\right)-L\right|<\varepsilon}}\left|d\left(x ; A_{k}, B_{k}\right)-L\right|^{p_{k}} \\
\leq & \frac{1}{h_{r}} \sum_{\substack{k \in I_{r} \\
\left|d\left(x ; A_{k}, B_{k}\right)-L\right| \geq \varepsilon}} \max \left\{M^{h}, M^{H}\right\} \\
& +\frac{1}{h_{r}} \sum_{\substack{\left|d\left(x ; A_{k}, B_{k}\right)-L\right|<\varepsilon \\
\leq}} \max \left\{(\varepsilon)^{p_{k}}\right\} \\
& +\max \left\{M^{h}, M^{H}\right\} \cdot \frac{1}{h_{r}} \mid\left\{k \in \varepsilon^{h}, \varepsilon^{H}\right\} .
\end{aligned}
$$

Therefore, $\left\{A_{k}\right\} \stackrel{[W N]_{\theta}^{L(p)}}{\sim}\left\{B_{k}\right\}$.

Definition 2.2 Let $(X, \rho)$ be a metric space. For any non-empty closed subsets $A_{k}, B_{k} \subseteq X$, we say that the sequences $\left\{A_{k}\right\}$ and $\left\{B_{k}\right\}$ are strongly Cesàro asymptotically equivalent (in the sense of Wijsman) of multiplicity $L$ if for each $x \in X$,

$$
\lim _{n} \frac{1}{n} \sum_{k=1}^{n}\left|d\left(x ; A_{k}, B_{k}\right)-L\right|=0
$$

(denoted by $\left.\left\{A_{k}\right\} \stackrel{\left[W \sigma_{1}\right]}{\sim}\left\{B_{k}\right\}\right)$ and simply strongly Cesàro asymptotically equivalent (in the sense of Wijsman) if $L=1$.

Definition 2.3 Let $(X, \rho)$ be a metric space and $p=\left(p_{k}\right)$ be a sequence of positive real numbers. For any non-empty closed subsets $A_{k}, B_{k} \subseteq X$, we say that the sequences $\left\{A_{k}\right\}$ and $\left\{B_{k}\right\}$ are strongly Cesàro asymptotically $p$-equivalent (in the sense of Wijsman) of multiplicity $L$ if for each $x \in X$,

$$
\lim _{n} \frac{1}{n} \sum_{k=1}^{n}\left|d\left(x ; A_{k}, B_{k}\right)-L\right|^{p_{k}}=0
$$

(denoted by $\left\{A_{k}\right\} \stackrel{\left[W \sigma_{(p)}\right]}{\sim}\left\{B_{k}\right\}$ ) and simply strongly Cesàro asymptotically $p$-equivalent (in the sense of Wijsman) if $L=1$.

Theorem 2.4 Let $(X, \rho)$ be a metric space and $A_{k}, B_{k}$ be non-empty closed subsets of $X$. If $\theta=\left\{k_{r}\right\}$ is a lacunary sequence with $\liminf _{r} q_{r}>1$, then

$$
\left\{A_{k}\right\} \stackrel{\left[W \sigma_{(p)}\right]}{\sim}\left\{B_{k}\right\} \Rightarrow\left\{A_{k}\right\} \stackrel{[W N]_{\theta}^{L_{(p)}}}{\sim}\left\{B_{k}\right\}
$$


Proof Let $\liminf _{r} q_{r}>1$. Then there is $\delta>0$ such that $q_{r} \geq 1+\delta$ for all $r \geq 1$. Hence, for $\left\{A_{k}\right\} \stackrel{\left[W \sigma_{(p)}\right]}{\sim}\left\{B_{k}\right\}$

$$
\begin{aligned}
A_{r} & =\frac{1}{h_{r}} \sum_{k \in I_{r}}\left|d\left(x ; A_{k}, B_{k}\right)-L\right|^{p_{k}} \\
& =\frac{1}{h_{r}} \sum_{k=1}^{k_{r}}\left|d\left(x ; A_{k}, B_{k}\right)-L\right|^{p_{k}}-\frac{1}{h_{r}} \sum_{k=1}^{k_{r-1}}\left|d\left(x ; A_{k}, B_{k}\right)-L\right|^{p_{k}} \\
& =\frac{k_{r}}{h_{r}}\left(\frac{1}{k_{r}} \sum_{k=1}^{k_{r}}\left|d\left(x ; A_{k}, B_{k}\right)-L\right|^{p_{k}}\right)-\frac{k_{r-1}}{h_{r}}\left(\frac{1}{k_{r-1}} \sum_{k=1}^{k_{r-1}}\left|d\left(x ; A_{k}, B_{k}\right)-L\right|^{p_{k}}\right) .
\end{aligned}
$$

Since $h_{r}=k_{r}-k_{r-1}$, we have

$$
\frac{k_{r}}{h_{r}} \leq \frac{1+\delta}{\delta}
$$

this leads to

$$
\frac{1}{k_{r-1}} \sum_{k=1}^{k_{r-1}}\left|d\left(x ; A_{k}, B_{k}\right)-L\right|^{p_{k}} \quad \text { and } \quad \frac{1}{k_{r}} \sum_{k=1}^{k_{r}}\left|d\left(x ; A_{k}, B_{k}\right)-L\right|^{p_{k}}
$$

converging to zero. Therefore, $\left\{A_{k}\right\} \stackrel{[W N]_{\theta}^{L(p)}}{\sim}\left\{B_{k}\right\}$.

Theorem 2.5 Let $(X, \rho)$ be a metric space and $A_{k}, B_{k}$ be non-empty closed subsets of $X$. If $\theta=\left\{k_{r}\right\}$ is a lacunary sequence with $\lim _{\sup } q_{r}>1$, then

$$
\left\{A_{k}\right\} \stackrel{[W N]_{\theta}^{L(p)}}{\sim}\left\{B_{k}\right\} \Rightarrow\left\{A_{k}\right\} \stackrel{\left[W \sigma_{(p)}\right]}{\sim}\left\{B_{k}\right\}
$$

Proof Let $\lim \sup _{r} q_{r}<\infty$. Then there is an $M>0$ such that $q_{r}<M$ for all $r \geq 1$. Let $\left\{A_{k}\right\} \stackrel{[W N]_{\theta}^{L_{(p)}}}{\sim}\left\{B_{k}\right\}$ and $\varepsilon>0$. There exists $R>0$ such that for every $j \geq R$ and

$$
A_{j}=\frac{1}{h_{j}} \sum_{k \in I_{j}}\left|d\left(x ; A_{k}, B_{k}\right)-L\right|^{p_{k}} \leq \varepsilon .
$$

We can also find $H>0$ such that $A_{j}<H$ for all $j=1,2, \ldots$. Now let $t$ be any integer with satisfying $k_{r-1}<t \leq k_{r}$, where $r>R$. Then we can write

$$
\begin{aligned}
\frac{1}{t} \sum_{k=1}^{t}\left|d\left(x ; A_{k}, B_{k}\right)-L\right|^{p_{k}} \leq & \frac{1}{k_{r-1}} \sum_{k=1}^{k_{r}}\left|d\left(x ; A_{k}, B_{k}\right)-L\right|^{p_{k}} \\
= & \frac{1}{k_{r-1}}\left(\sum_{k \in I_{1}}\left|d\left(x ; A_{k}, B_{k}\right)-L\right|^{p_{k}}+\sum_{k \in I_{2}}\left|d\left(x ; A_{k}, B_{k}\right)-L\right|^{p_{k}}\right. \\
& \left.+\cdots+\sum_{k \in I_{r}}\left|d\left(x ; A_{k}, B_{k}\right)-L\right|^{p_{k}}\right)
\end{aligned}
$$




$$
\begin{aligned}
= & \frac{k_{1}}{k_{r-1}} A_{1}+\frac{k_{2}-k_{1}}{k_{r-1}} A_{2}+\cdots+\frac{k_{R}-k_{R-1}}{k_{r-1}} A_{R} \\
& +\frac{k_{R+1}-k_{R}}{k_{r-1}} A_{R+1}+\cdots+\frac{k_{r}-k_{r-1}}{k_{r-1}} A_{r} \\
\leq & \left\{\sup _{j \geq 1} A_{j}\right\} \frac{k_{R}}{k_{r-1}}+\left\{\sup _{j \geq 1} A_{j}\right\} \frac{k_{r}-k_{R}}{k_{r-1}} \\
\leq & H \cdot \frac{k_{B}}{k_{r-1}}+\varepsilon M .
\end{aligned}
$$

This completes the proof.

\section{Competing interests}

The authors declare that they have no competing interests.

\section{Authors' contributions}

All authors contributed equally to the writing of this paper. All authors read and approved the final manuscript.

\section{Author details}

'Department of Mathematics, Faculty of Science and Literature, Afyon Kocatepe University, Afyonkarahisar, 03200, Turkey.

${ }^{2}$ Department of Mathematics, Istanbul Commerce University, Sutluce, Istanbul, Turkey.

\section{Acknowledgements}

We would like to express our gratitude to the referee of the paper for his useful comments and suggestions towards the quality improvement of the paper. This paper was presented during the International Conference On Applied Analysis and Mathematical Modelling (ICAAMM2013) held in Istanbul, Turkey, on June 2-5, 2013 and submitted for conference proceedings.

\section{Received: 24 September 2013 Accepted: 25 February 2014 Published: 31 Mar 2014}

\section{References}

1. Baronti, M, Papini, P: Convergence of sequences of sets. In: Methods of Functional Analysis in Approximation Theory. ISNM, vol. 76, pp. 135-155. Birkhäuser, Basel (1986)

2. Beer, G: On convergence of closed sets in a metric space and distance functions. Bull. Aust. Math. Soc. 31, 421-432 (1985)

3. Beer, G: Wijsman convergence: a survey. Set-Valued Var. Anal. 2, 77-94 (1994)

4. Nuray, F, Rhoades, BE: Statistical convergence of sequences of sets. Fasc. Math. 49, 87-99 (2012)

5. Ulusu, U, Nuray, F: Lacunary statistical convergence of sequence of sets. Prog. Appl. Math. 4(2), 99-109 (2012)

6. Ulusu, U, Nuray, F: On asymptotically lacunary statistical equivalent set sequences. J. Math. 2013, Article ID 310438 (2013)

7. Wijsman, RA: Convergence of sequences of convex sets, cones and functions. Bull. Am. Math. Soc. 70, 186-188 (1964)

8. Wijsman, RA: Convergence of sequences of convex sets, cones and functions II. Trans. Am. Math. Soc. 123(1), 32-45 (1966)

9. Fridy, JA, Orhan, C: Lacunary statistical convergence. Pac. J. Math. 160(1), 43-51 (1993)

10. Marouf, M: Asymptotic equivalence and summability. Int. J. Math. Sci. 16(4), 755-762 (1993)

11. Patterson, RF: On asymptotically statistically equivalent sequences. Demonstr. Math. 36(1), 149-153 (2003)

12. Patterson, RF, Savaş, E: On asymptotically lacunary statistically equivalent sequences. Thai J. Math. 4, 267-272 (2006)

13. Savaş, E, Patterson, RF: An extension asymptotically lacunary statistically equivalent sequences. Aligarh Bull. Math. 27(2), 109-113 (2008)

14. Savaş, E: On $\mathcal{I}$-asymptotically lacunary statistical equivalent sequences. Adv. Differ. Equ. 2013, Article ID 111 (2013)

15. Fridy, JA: On statistical convergence. Analysis 5, 301-313 (1985)

16. Freedman, AR, Sember, JJ, Raphael, M: Some Cesàro type summability spaces. Proc. Lond. Math. Soc. 37, 508-520 (1978)

10.1186/1029-242X-2014-134

Cite this article as: Ulusu and Savaş: An extension of asymptotically lacunary statistical equivalence set sequences Journal of Inequalities and Applications 2014, 2014:134 